\title{
Obstetric emergencies: preparedness among nurses for safe motherhood
}

\author{
Shraddha Verma, Manisha Jain*, Chhaya Budhwani
}

Department of Obstetrics \& Gynecology, PCMS \& RC, Bhopal, MP, India

Received: 13 March 2016

Revised: 22 March 2016

Accepted: 26 March 2016

\section{*Correspondence:}

Dr. Manisha Jain,

E-mail: mnishu2002@yahoo.com

Copyright: ( ) the author(s), publisher and licensee Medip Academy. This is an open-access article distributed under the terms of the Creative Commons Attribution Non-Commercial License, which permits unrestricted non-commercial use, distribution, and reproduction in any medium, provided the original work is properly cited.

\section{ABSTRACT}

Background: Obstetric emergencies may turn catastrophic in women's as well as obstetrician's life. In the event of real emergency, all prior preparations may fall deficient. Every little contribution towards safe confinement brings about large reductions in maternal mortality and morbidity.

Methods: Cross-sectional questionnaire based study carried out on nurses involved in perinatal care of parturient conducted at the Dept of Obstetrics \& Gynecology of PCMS \& RC, Bhopal.

Results: Total study participants were 36 (100\% response rate). Majority (83\%) were aware about the two leading causes of maternal mortality (PE, PPH). Twenty four $(67 \%)$ knew the warning signs of eclampsia and $61 \%$ knew the signs of eclampsia but only $17 \%$ were aware of $\mathrm{MgSO}_{4}$ toxicity. Only $56 \%$ could correctly prepare the loading dose of $\mathrm{MgSO}_{4}$. All were aware about PPH; however only17\% knew methergine as the drug for active management. Grossly wrong attitude noted only in $27 \%$ for PPH and $27 \%$ for severe PE. Overall preparedness for emergency was satisfactory in LR and PNC.

Conclusions: Though the overall awareness for identifying emergencies (PE, PPH) was satisfactory, lacunae in awareness were noted about components of eclampsia, magnesium toxicity and drugs required for initial management of PE and PPH. Preparedness of nurses in labour room and postnatal ward was fairly good. Regular assessment of awareness \& preparedness for obstetric emergencies would be desirable to optimize the overall delivery outcomes especially at peripheral rural centres where nurses are primarily involved in the care of labouring women.

Keywords: Preparedness, Labour, Obstetric emergencies

\section{INTRODUCTION}

Pregnancy is a normal healthy state that most women aspire to at some point in their life. Emergency obstetric care is a set of critical lifesaving functions commonly called signal functions provided by a health care facility throughout the day and week. Obstetric complications can neither be predicted nor be prevented but can be managed by timely provision of life saving services. Obstetric emergencies may turn catastrophic in women's as well as obstetrician's life. In the event of real emergency, all prior preparations may fall deficient. Maternal death is usually the end result of inadequately or inappropriately managed complications arising during pregnancy and child birth.

Although we have registered a significant fall in maternal mortality ratio from 725 (1982) to 212 (2011) yet to achieve the target of Millennium Development Goal (200 per lakh live births). ${ }^{7}$ Postpartum hemorrhage and preeclampsia (PPH and PE) are the leading causes of maternal mortality accounting for about $25 \%$ and $12 \%$ of maternal deaths respectively. ${ }^{1,2}$

The time of onset of life threatening complications to receive appropriate treatment encounters delay at three 
stages: 1) Failure to recognize the significance of problem by the women and her family. 2) Delay in referral due to distances, difficult access or transport facilities. 3) Delay in initiating the treatment once woman reaches the facility. In our study, we are assessing the cause for 3rd delay where gap exists in identification, prompt action or preparedness of emergency unit for such emergencies. Proper knowledge about identification signs, emergency measures to be taken and well equipped obstetric unit can reduce maternal mortality by almost 35 $40 \% .^{3}$ As the nurses form an integral component of our health care system, their awareness and preparedness for obstetric emergencies attains paramount importance.

Current study was undertaken to assess the awareness and preparedness of nurses for Pre-eclampsia and post-partum hemorrhage, the two leading causes of maternal mortality in our country.

\section{METHODS}

This was a cross sectional study conducted in the Department of Obstetrics and Gynecology of medical college hospital of central India in the year 2014. The study was approved by the institutional ethics committee. A multiple choice based questionnaire was used for the assessment of preparedness of nursing staff for the obstetrics emergencies. The questionnaire was divided into three sections.

a) Assessed the clinical knowledge of nurses for identification of the two obstetrics emergencies.

b) Assessed the attitude and initial response after identification of emergencies.

c) Audited the overall preparedness of nurses working in labour room and postnatal ward for such emergencies.

All nurses providing obstetric care to the women in labour and post natal period were offered voluntary participation in the study after explaining about the items of questionnaire in detail. The study participants could opt out of the study at any point of time and stage of the study. Written informed consent from all study participants was obtained. The items in questionnaire were graded to assign the scores and overall analysis was done according to the choices made by them.

\section{RESULTS}

The questionnaire was administered to $36(\mathrm{~N})$ nurses of which all agreed to participate in the study $(100 \%$ response rate). The questionnaires were collected, data was analysed and results were computed. Majority of nurses $(92 \%)$ had total working experience of less than two years either in a government or a private hospital.

\section{Awareness about pre-eclampsia (PE)}

Although all study participants were aware of the two emergencies, only $36 \%$ knew them as the leading causes of maternal mortality. Regarding pre-eclampsia, about $61 \%$ knew all the components of eclampsia correctly and $67 \%$ were aware of warning signs of pre-eclamsia. Although $56 \%$ knew the loading dose of $\mathrm{MgSO}_{4}$, only $16.67 \%$ were totally aware of $\mathrm{MgSO}_{4}$ toxicity. The Scores were calculated about awareness of PE and it was noted that only $36 \%$ nurses could score between 11-15 whereas $8 \%$ nurses scored poorly (Table 1, Figure 1).

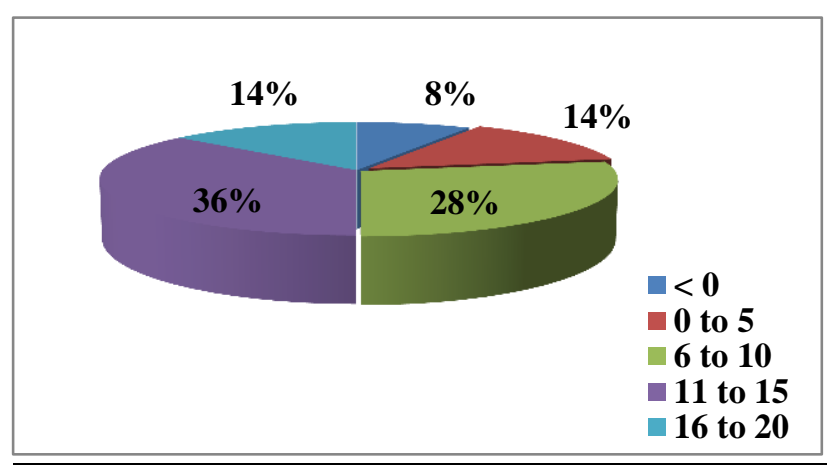

Figure 1: Awareness about preeclampsia in relation to scores.

\section{Awareness about postpartum hemorrhage (PPH)}

On similar assessment about PPH, we observed that almost all (100\%) were able to define PPH. Majority (90\%) knew methargin as the drug of choice for active management. Correct drug content of oxytocin ampoule was known to $61 \%$ whereas cautions to be taken while administering prostaglandins was correctly opted by $47 \%$ nurses. Overall scores of awareness about PPH ranged between 11-15 among 36\% while below 0 among $6 \%$ of nurses (Table 2, Figure 2).

Table 1: Awareness about preeclampsia.

\begin{tabular}{|lllll|l|}
\hline $\begin{array}{l}\text { Sr. } \\
\text { No. }\end{array}$ & $\begin{array}{l}\text { Items related to Pre-eclampsia } \\
\text { awareness (scores) }\end{array}$ & $\begin{array}{l}\text { Correct } \\
(4)\end{array}$ & $\begin{array}{l}\text { Partially } \\
\text { correct }(2)\end{array}$ & $\begin{array}{l}\text { Incorrect } \\
(-2)\end{array}$ & $\begin{array}{l}\text { Not attempted } \\
(0)\end{array}$ \\
\hline 1 & As a leading causes of maternal mortality & $13(36 \%)$ & $17(47 \%)$ & $6(17 \%)$ & - \\
\hline 2 & Components of eclampsia & $22(61 \%)$ & $4(11 \%)$ & $10(28 \%)$ & - \\
\hline 3 & Warning signs of pre-eclampsia & $24(67 \%)$ & $10(28 \%)$ & $2(6 \%)$ & - \\
\hline 4 & Signs of $\mathrm{MgSO}_{4}$ toxicity & $6(17 \%)$ & $17(47 \%)$ & $13(36 \%)$ & - \\
\hline 5 & loading dose of $\mathrm{MgSO}_{4}$ & $20(56 \%)$ & $10(28 \%)$ & $6(17 \%)$ & - \\
\hline
\end{tabular}


Table 2: Awareness about post-partum hemorrhage.

\begin{tabular}{|lllll|l|}
\hline $\begin{array}{l}\text { Sr. } \\
\text { No. }\end{array}$ & Awareness about PPH & $\begin{array}{l}\text { Correct } \\
(4)\end{array}$ & $\begin{array}{l}\text { Partially } \\
\text { correct }(2)\end{array}$ & $\begin{array}{l}\text { Incorrect } \\
(-2)\end{array}$ & $\begin{array}{l}\text { Not attempted } \\
(0)\end{array}$ \\
\hline 1 & Identification of PPH & $36(100 \%)$ & - & - & - \\
\hline 2 & Drug for active management & $6(17 \%)$ & $26(72 \%)$ & $4(11 \%)$ & - \\
\hline 3 & Awareness about oxytocin & $22(61 \%)$ & - & $11(31 \%)$ & $3(8 \%)$ \\
\hline 4 & Awareness about prostaglandin PGF2 $\alpha$ & $17(47 \%)$ & - & $19(53 \%)$ & - \\
\hline 5 & PPH as cause of Maternal death & $24(67 \%)$ & - & $12(33 \%)$ & - \\
\hline
\end{tabular}

Table 3: Attitude towards obstetric emergencies (PE \& PPH).

\begin{tabular}{|llllll|}
\hline $\begin{array}{l}\text { Sr. } \\
\text { No. }\end{array}$ & $\begin{array}{l}\text { Attitude in managing clinical } \\
\text { conditions related to PE and PPH }\end{array}$ & Right & Partially right & Negligent & Grossly wrong \\
\hline 1 & Eclampsia & $20(56 \%)$ & $5(14 \%)$ & $8(22 \%)$ & $3(8 \%)$ \\
\hline 2 & PNC with impending eclampsia & $21(58 \%)$ & $6(17 \%)$ & $2(6 \%)$ & $7(19 \%)$ \\
\hline 3 & Post-partum hemorrhage & $20(56 \%)$ & $10(28 \%)$ & $2(6 \%)$ & $4(11 \%)$ \\
\hline 4 & APH with shock & $22(61 \%)$ & $8(22 \%)$ & $4(11 \%)$ & $2(6 \%)$ \\
\hline 5 & PNC with haematoma & $16(44 \%)$ & $13(36 \%)$ & $3(8 \%)$ & $4(11 \%)$ \\
\hline
\end{tabular}

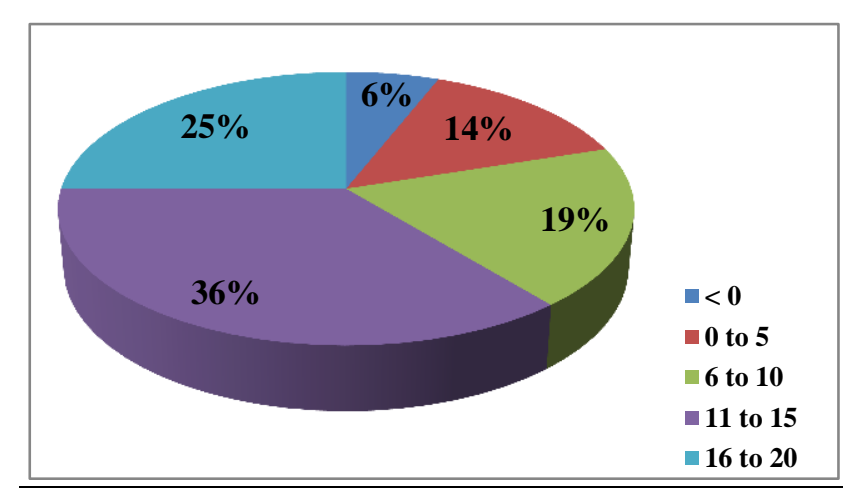

Figure 2: Awareness about post-partum hemorrhage in relation to scores.

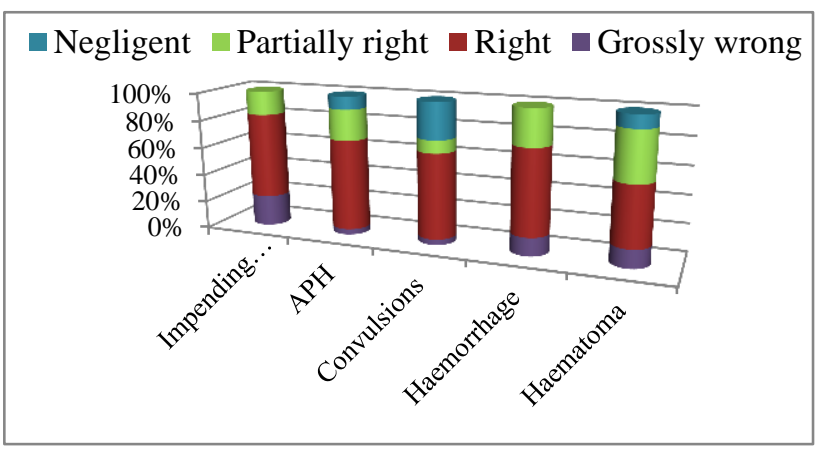

Figure 3: Attitude towards obstetric emergencies (PE \& PPH).

\section{Attitude towards obstetric emergencies PE and PPH}

The attitude of study participants in different emergency conditions and their promptness to take action was assessed. Overall, 56\% correctly responded to conditions of ANC with convulsions and PNC with haemorrhge.
Around $8 \%$ showed grossly wrong attitude in managing convulsions and $11 \%$ in managing haemorrhage in a Post natal case. Almost 58\% showed promptness in managing a woman with impending eclampsia. More than $50 \%$ were having correct attitude for managing PNC with haematoma (Table 3, Figure 3).

\section{Preparedness for obstetric emergencies among nurses}

Overall preparedness among nurses for obstetric emergencies in labour room and postnatal ward was assessed. About $87 \%$ were correctly aware about the availability of emergency kit in wards, 93\% were aware about the storage place of emergency tray in case of emergency and $70 \%$ were aware about the availability of drugs in emergency tray. About $77 \%$ were correctly aware about the quantity of emergency medications available and were doing a check of expiry of emergency medications (Table 4).

Table 4: Preparedness for obstetric emergencies among nurses.

\begin{tabular}{|lll|}
\hline A wareness of nurses for & Yes & No \\
\hline Storage of emergency tray & $28(93 \%)$ & $2(7 \%)$ \\
\hline $\begin{array}{l}\text { Availability of drugs in } \\
\text { emergency tray }\end{array}$ & $21(70 \%)$ & $9(30 \%)$ \\
\hline Quantity \& expiry of drugs & $23(77 \%)$ & $7(23 \%)$ \\
\hline Emergency kit & $26(87 \%)$ & $4(13 \%)$ \\
\hline Functional $\mathrm{O}_{2}$ supply & $29(97 \%)$ & $1(3 \%)$ \\
\hline
\end{tabular}

\section{DISCUSSION}

Pregnant women because of their special physical and psychological needs are particularly vulnerable to life altering events during labour and postpartum period. Unfortunately all preparations made in advance can fall 
short at the time of real emergency or may have to be drastically altered in the event of true emergency. Adequate preparedness and readiness for managing emergency crisis can significantly alter the survival of women in labour or postpartum. Nursing staff form an integral and important component of maternal health care delivery system and their contribution in the event of complication as a part of team can be of paramount significance. In our country, where we are already facing the challenge of ensuring institutional delivery for all, the role of paramedical and nursing staff further becomes important in curtailing down the MMR.

In the study conducted by Mariyam Sarfraz and Saima Hamid, the authors highlighted the gaps between the technical knowledge and clinical skills of community mid wife's resulting in a sub optimally trained health worker, not prepared to work in the resource poor community setting. ${ }^{4}$ Quantitative assessments of community midwives and their training schools from several districts of Pakistan revealed that the CMWs began their work with inadequate knowledge and skills. A skill assessment of 106 CMWs from six rural districts showed that trained CMWs lack knowledge of and basic skills relevant to maternal and new-born care. ${ }^{5}$ In our study although overall awareness about PE and PPH, the leading "killers" was fairly good yet we observed poor scores in early identification of eclampsia and preeclampsia in about $30 \%$ of staff. Similarly, for PPH, awareness about commonly used oxytocics was seen fairly in about two third of staff only.

In a study conducted by Baack $\mathrm{S}$, et al authors revealed that most nurses were not confident in their abilities to respond to major disaster events. The nurses who were confident were more likely to have had actual prior experience in disasters or shelters. ${ }^{6}$ In our study, the attitude or initial response of study participants in different emergency situations of PE and $\mathrm{PPH}$ was correctly noted in only half $(56 \%)$ of the staff.

In our study, overall preparedness in wards and labour room for obstetric emergencies was fair in terms of awareness about emergency drugs, their availability, their functional status and expiry. A regular check or audit of preparedness can cut short the response time in wake of real emergency situations.

\section{CONCLUSIONS}

Though the overall awareness for identifying emergencies (PE, PPH) was satisfactory, lacunae in awareness were noted about components of eclampsia, magnesium toxicity and drugs required for initial management of PE and PPH. Preparedness of nurses in labour room and postnatal ward was fairly good. Regular assessment of awareness \& preparedness for obstetric emergencies would be desirable to optimize the overall delivery outcomes especially at peripheral rural centres where nurses are primarily involved in the care of labouring women.

\section{Funding: No funding sources}

Conflict of interest: None declared

Ethical approval: The study was approved by the Institutional Ethics Committee

\section{REFERENCES}

1. Centers for disease control and prevention and health resources and service administration: maternal, infant and child health. In: healthy people, conference ed Atlanta, CDC 2000. 2010.

2. Special bulletin on maternal mortality in India 200709. Sample registration system, office of registrar general of India, vital statistics division, R K Puram, New Delhi. 2011.

3. Park K. Health programs in India. In Park's text book of preventive and Social Medicine, 20th edn, Bhanot publishers, Jablpur, India. 2009:359-392.

4. Sarfraz M, Hamid S. Challenges in delivery of skilled maternal care-experiences of community midwives in Pakistan BMC Pregnancy and Childbirth. 2014;14:59.

5. Wajid A, Mir MA, Rashid Z. Assessing the potential acceptability of a new cadre of community midwives for pregnancy and delivery related care in rural Pakistan-findings from a qualitative study. Islamabad, Pakistan. 2010.

6. Baack S. Nurses' preparedness and perceived competence in managing disasters. J Nurs Scholarsh. 2013;45(3):281-7.

7. The Millennium development goal's report, New York, United States. 2007.

Cite this article as: Verma S, Jain M, Budhwani C. Obstetric emergencies: preparedness among nurses for safe motherhood. Int J Reprod Contracept Obstet Gynecol 2016;5:998-1001. 